\title{
Corals from the Persian/Arabian Gulf as models for thermotolerant reef-builders: Prevalence of clade C3 Symbiodinium, host fluorescence and ex situ temperature tolerance
}

\author{
B. Hume ${ }^{\text {a }}$, C. D'Angelo ${ }^{\mathrm{a}}$, J. Burt ${ }^{\text {b }}$, A.C. Baker ${ }^{\text {c }}$, B. Riegl ${ }^{\mathrm{d}}$, J. Wiedenmann ${ }^{\mathrm{a}, *}$ \\ a National Oceanography Centre, Southampton (NOCS), University of Southampton, European Way, SO143ZH Southampton, UK \\ ${ }^{\mathrm{b}}$ Biology Department, New York University - Abu Dhabi, PO Box 129 188, Abu Dhabi, United Arab Emirates \\ ${ }^{\mathrm{c}}$ Division of Marine Biology and Fisheries, Rosenstiel School of Marine and Atmospheric Science, University of Miami, 4600 Rickenbacker Cswy., Miami, FL 33149, USA \\ ${ }^{\mathrm{d}}$ Nova Southeastern University Oceanographic Center, 8000 North Ocean Drive Dania Beach, FL 33004, USA
}

\section{A R T I C L E I N F O}

Keywords:

Coral reefs

Global warming

Bleaching

Zooxanthellae

Green fluorescent protein

Heat stress

\begin{abstract}
A B S T R A C T
Corals in the Arabian/Persian Gulf endure summer temperatures of up to $36^{\circ} \mathrm{C}$, making them ideal subjects to study the mechanisms underlying thermal tolerance. Unexpectedly, we found the "generalist" Symbiodinium clade C3 to be the prevalent symbiont among seven coral species from Abu Dhabi (UAE) waters. Moreover, C3 represented the only dominant symbiont type in Porites spp. from this region. The "thermotolerant" symbionts D1a and C15 were not encountered, indicating that the association with these symbionts cannot be the sole reason for the heat tolerance of Gulf corals. The association of Porites lobata with specific symbiont types (C3 vs. C15) in samples from habitats with very different temperature regimes (Abu Dhabi vs. Fiji) remained unaffected by laboratory culture. During temperature stress experiments specimens from both locations strongly downregulated green fluorescent protein (GFP)-like pigments. However, the Abu Dhabi samples were less prone to bleaching and showed lower mortality.
\end{abstract}

Crown Copyright (c) 2012 Published by Elsevier Ltd. All rights reserved.

\section{Introduction}

Hermatypic corals are primarily responsible for the formation of modern reefs that succeed in oligotrophic waters due to the lightdependent symbiosis with unicellular dinoflagellate algae (zooxanthellae) belonging to the genus Symbiodinium (Muscatine, 1990). Several environmental factors such as changes in light levels and seawater temperature can trigger the loss of zooxanthellae from the host (Baker et al., 2008; Brown, 1997; Douglas, 2003). When the visual appearance of the coral becomes dominated by the white colour of the skeleton showing through the tissue, the phenomenon is known as "bleaching". Bleaching due to thermal stress is considered to be induced by the algal production of reactive oxygen species (ROS), particularly $\mathrm{H}_{2} \mathrm{O}_{2}$ (Lesser, 2006; Smith et al., 2005; Suggett et al., 2008; Tchernov et al., 2011). Although the animal host might survive and recover, mass mortality is frequently observed among bleached corals (Baker et al., 2008; Glynn, 1996; Wilkinson, 1998). Over the past decades, mass bleaching events associated with elevated seawater temperatures have become more frequent and have contributed to the rapid degradation of coral reefs (Baker et al., 2008; Burt et al., 2011; Hughes et al.,

\footnotetext{
* Corresponding author. Tel.: +44 (0)23 8059 6497, mobile: +44 (0)7912564356; fax: +44 (0)2380593059.

E-mail address: joerg.wiedenmann@noc.soton.ac.uk (J. Wiedenmann).
}

2003). Currently, an estimated $30 \%$ of reefs are severely damaged and $>50 \%$ may be lost within the next two decades according to climate predictions (Hughes et al., 2003; Sheppard, 2003).

In general, temperatures as little as $1{ }^{\circ} \mathrm{C}$ above the average annual maximum can trigger bleaching, but the actual bleaching threshold depends also on the duration of temperature stress and the stress history of the corals (Baker et al., 2008; Glynn, 1996). Furthermore, the threshold for heat-induced bleaching can be lowered by unfavourable concentrations of inorganic nutrients in the water column (Wiedenmann et al., 2012). Particularly, elevated levels of dissolved inorganic nitrogen can increase bleaching susceptibility (Wagner et al., 2010; Wiedenmann et al., 2012; Wooldridge, 2009) and this may be exacerbated by higher densities of symbionts in nutrient-enriched corals (Cunning and Baker, 2012).

Symbiotic corals can acclimatise or adapt to temperature stress (Coles and Brown, 2003). While many coral reefs experience maximal temperatures of $\sim 29^{\circ} \mathrm{C}$ and annual temperature fluctuations of $\sim 4{ }^{\circ} \mathrm{C}$ some coral communities within the Gulf of Oman and the Arabian/Persian Gulf (hereafter called "the Gulf") can cope with exceptionally high seasonal temperature maxima $\left(32-36^{\circ} \mathrm{C}\right)$ as well as daily (up to $9^{\circ} \mathrm{C}$ ) and annual $\left(\sim 20^{\circ} \mathrm{C}\right.$ ) fluctuations (Coles, 1997, 2003; Kinsman, 1964; Riegl et al., 2011) (Fig. 1 and Table 1). The existence of these coral communities makes it evident that at least some hermatypic corals can survive under conditions that are predicted elsewhere as a result of global warming within the next 

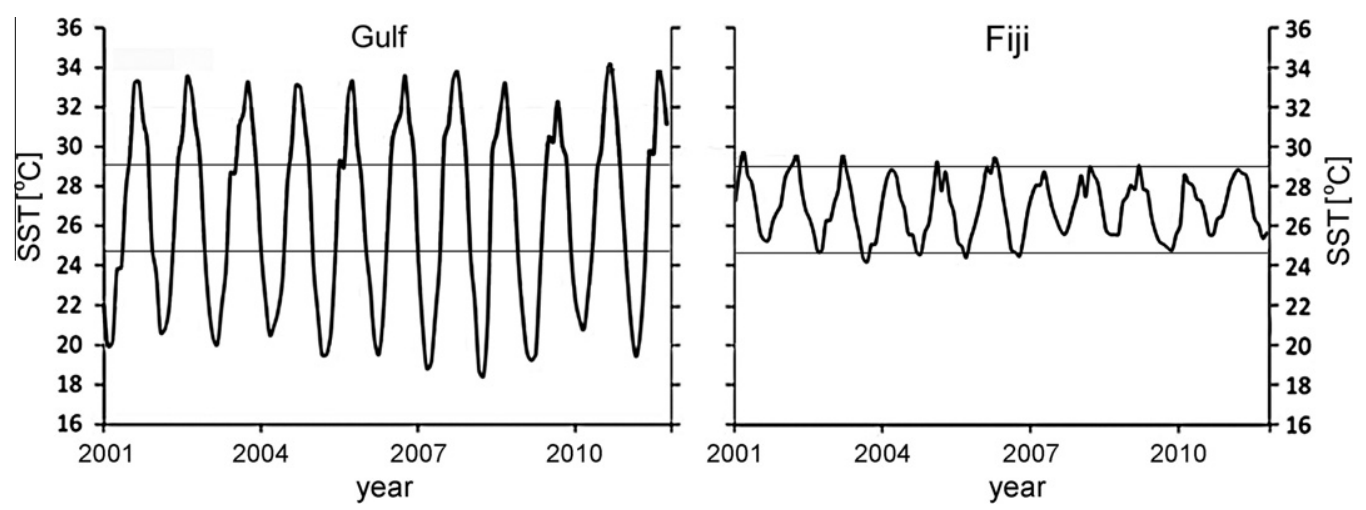

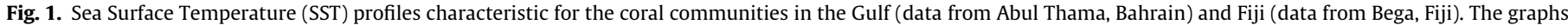

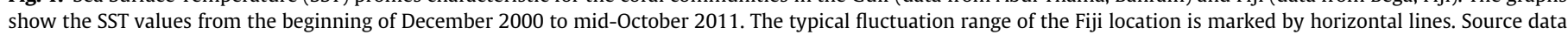
retrieved from NOAA Coral Reef Watch (http://coralreefwatch.noaa.gov/satellite/index.html) for 50-km Satellite Virtual Stations.

Table 1

Temperature regimes of coral habitats in the Gulf and selected regions elsewhere.

\begin{tabular}{|c|c|c|c|c|}
\hline Region & Site $^{a}$ & $\operatorname{Max} T^{\mathrm{b}}$ & $\operatorname{Min} T^{\mathrm{b}}$ & Annual $\Delta T^{\mathrm{b}}$ \\
\hline Persian Gulf & $\begin{array}{l}\text { Abu Dhabi, UAE }{ }^{c} \\
\text { Abul Thama, Bahrain }\end{array}$ & $\begin{array}{l}36.0 \\
32.0\end{array}$ & $\begin{array}{l}16.0 \\
19.2\end{array}$ & $\begin{array}{l}20.0 \\
12.8\end{array}$ \\
\hline Gulf of Oman & Muskat, Oman & 30.2 & 23.0 & 7.2 \\
\hline Western Indian Ocean & $\begin{array}{l}\text { Mahe, Seychelles } \\
\text { Chagos Archipelago } \\
\text { Mombasa, Kenya } \\
\text { Blue Bay, Mauritius } \\
\text { Lakshadweep, India } \\
\text { Ningaloo, Australia }\end{array}$ & $\begin{array}{l}29.4 \\
29.2 \\
29.2 \\
27.7 \\
29.6 \\
28.2\end{array}$ & $\begin{array}{l}25.4 \\
26.8 \\
25.0 \\
23.0 \\
27.3 \\
23.4\end{array}$ & $\begin{array}{l}4.0 \\
2.4 \\
4.2 \\
4.7 \\
2.3 \\
4.8\end{array}$ \\
\hline Indo-Pacific & $\begin{array}{l}\text { East coast, Taiwan } \\
\text { Apo Reef, Philippines } \\
\text { Wakatobi, Indonesia }\end{array}$ & $\begin{array}{l}29.0 \\
29.7 \\
29.6\end{array}$ & $\begin{array}{l}23.9 \\
27.0 \\
27.0\end{array}$ & $\begin{array}{l}5.1 \\
2.7 \\
2.6\end{array}$ \\
\hline Pacific Ocean & $\begin{array}{l}\text { Beqa, Fiji } \\
\text { Heron Island, Australia } \\
\text { Davies Reef, Australia } \\
\text { Oahu, Hawaii, USA }\end{array}$ & $\begin{array}{l}28.0 \\
27.3 \\
24.0 \\
27.0\end{array}$ & $\begin{array}{l}24.6 \\
21.5 \\
28.5 \\
24.2\end{array}$ & $\begin{array}{l}3.4 \\
5.8 \\
4.5 \\
2.8\end{array}$ \\
\hline Atlantic Ocean & $\begin{array}{l}\text { US Virgin Islands, USA } \\
\text { Abrolhos Reefs, Brazil } \\
\text { Bermuda } \\
\text { Palm Beach, USA }\end{array}$ & $\begin{array}{l}28.5 \\
28.0 \\
27.0 \\
29.0\end{array}$ & $\begin{array}{l}25.8 \\
24.6 \\
19.6 \\
24.2\end{array}$ & $\begin{array}{l}2.7 \\
3.4 \\
7.4 \\
4.8\end{array}$ \\
\hline
\end{tabular}

a NOAA Coral Reef Watch 50-km Satellite Virtual Station http://coralreefwatch.noaa.gov/satellite/vs/index.html.

b Max T: Maximum mean Temperature, Min T: Minimum mean Temperature, Annual DT: Annual Temperature Oscillation. All values given in degrees ${ }^{\circ} \mathrm{C}$.

c Data from Coles (2003).

centuries. Gulf corals have been subjected to a hotter climate than other corals for only $\sim 6$ ka years (Purkis et al., 2010), over which period the observed heat resistance presumably developed. The understanding of the mechanisms underlying this acclimatisation/adaptation potential is of crucial importance to accurately forecast the global fate of coral reefs.

The heat stress tolerance of corals could potentially be supported at different levels, for instance by the protection of cellular components through an enhanced antioxidant defense (Lesser, 1996) or elevated level of heat shock proteins (Choresh et al., 2004) or by higher levels of photoprotective substances such as mycosporine-like amino acids (Dunlap and Shick, 1998) or green fluorescent protein (GFP)-like pigments (Dove et al., 2001; Salih et al., 2000). Yet another strategy might be to host symbiont communities dominated by thermotolerant symbionts, either by the uptake of new symbionts after a bleaching event or by changing the relative abundance of symbiont types already present in the host (symbiont shuffling) (Baker, 2001; Baker et al., 2004; Berkelmans and van Oppen, 2006; Buddemeier and Fautin, 1993; Jones et al., 2008; Rowan et al., 1997). However, it is not yet established whether the observed acclimatisation will allow the corals to sur- vive in the long run since only $23 \%$ of coral species may be able to change their symbionts (Goulet, 2006, 2007). A study conducted in 2000-2001 found that $60 \%$ of the sampled coral colonies from the Gulf were associated with Symbiodinium Clade D, a zooxanthellae strain considered to be thermotolerant (Baker et al., 2004). Clade D symbionts were also detected in corals off the Iranian coast (Ghavam Mostafavi et al., 2007; Shahhosseiny et al., 2011). Hence, the resilience of corals from the Gulf was considered to be at least partially due to the association with this particular Symbiodinium clade.

Here, we have examined the dominant symbiont clades in seven corals species (Cyphastrea microphthalma, Favia pallida, Platygyra daedalea, Porites harrisoni, Porites lobata, Porites lutea and Acropora clathrata) growing off the Abu Dhabi coast (UAE) to extend the data set on zooxanthellae associated with heat tolerant corals. We report that the "generalist" C3 is the prevalent Symbiodinium in these corals, rather than members of clade $\mathrm{D}$, indicating that the association with these symbionts cannot be the sole reason for the heat tolerance of Gulf corals. Hence, the more complex mechanisms underlying the thermal tolerance of Gulf corals call for further experimental studies. 
Molecular and physiological analyses under tightly controlled laboratory conditions hold great promise to improve the knowledge about the mechanisms underlying the heat tolerance of reef corals (D'Angelo and Wiedenmann, 2012). While other fields of (molecular) biology rely heavily on the thorough analysis of a few model organisms, at the moment there are not many coral models for laboratory studies (Weis et al., 2008). However, recent progress in coral culture enables the propagation of these organisms in excellent physiological conditions over many years or even decades (D'Angelo and Wiedenmann, 2012; Leewis and Janse, 2008) and experiments with laboratory strains have already yielded important insights into physiological processes in reef corals (Allemand et al., 2004; D’Angelo et al., 2012, 2008; Wiedenmann et al., 2012).

Corals from the Gulf region, for instance $P$. lobata, are of great importance as reef builders because they have a wide global distribution (Veron, 2000). They offer the opportunity for comparative studies and thus represent excellent models to study the capacity of corals to adapt to increasing water temperatures. Here, we characterised $P$. lobata from Abu Dhabi (UAE) reefs adapted to maximal monthly mean temperatures of $\sim 34{ }^{\circ} \mathrm{C}$ as laboratory model for heat stress tolerance. For comparison, we analysed conspecifics from Fijian reefs (Pacific Ocean) where maximal monthly mean temperatures usually do not exceed $28^{\circ} \mathrm{C}$ (Coles, 2003) (Fig. 1). We succeeded in establishing laboratory cultures of $P$. lobata from these two regions and have propagated them by fragmentation over 2 years in the coral mesocosm at the Coral Reef Laboratory at the University of Southampton, UK (D'Angelo and Wiedenmann, 2012). Furthermore, we examined the effects of long-term aquarium culture on the community structure and stability of algal symbionts in these corals.

Tissue levels of GFP-like proteins respond to a variety of stimuli such as altered light levels, mechanical damage or the presence of epibionts; which makes these pigments easily accessible biomarkers of environmental stress (D'Angelo et al., 2012, 2008). Hence, we have tested how GFP-like host pigments respond to elevated temperatures and evaluated their suitability as intrinsic heat stress markers in P. lobata. We present a thorough spectrometric characterisation of the GFP-like complement in P. lobata that establishes their downregulation in response to temperature stress. The wellcharacterised laboratory models presented in this paper will facilitate future studies of the mechanisms underlying thermal tolerance of hermatypic corals.

\section{Materials and methods}

\subsection{Coral material, collection and culture}

Field identification relied on local experts. Fragments of UAE and Fiji samples that were identified as $P$. lobata during field collection were bleached in sodium hypochlorite solution and inspected under a microscope (MZ10, Leica). Analysis of the corallite structure (Veron, 2000) confirmed the field identification of these samples. The samples were distinguishable from $P$. lutea by the lack of a protruding ring of five tall pali, and from $P$. solida by the lack of a flattened columella. However, the identifications need to be considered within the limits set by the taxonomic value of skeletal features among Porites spp. (Forsman et al., 2009).

Samples for Symbiodinium analyses were removed from colonies of C. microphthalma, P. daedalea, F. pallida, P. lobata, P. harrisoni and $A$. clathrata located in 4-6 $\mathrm{m}$ depth on Saadiyat reef and Dhabiya reefs, $15 \mathrm{~km}$ northeast and $30 \mathrm{~km}$ southwest of Abu Dhabi city, respectively, on 6 October 2010. Material was collected from colonies that were situated at least $10 \mathrm{~m}$ apart from each other, frozen and stored at $-80^{\circ} \mathrm{C}$. Subsamples were shipped in RNA later $^{\mathrm{TM}}$ to the University of Southampton for further analyses. Additional samples of $P$. lobata, $P$. harrisoni and $P$. lutea were collected on 17 September 2012 on Saadiyat reef and fixed in EtOH (p.a.) immediately after collection.

Specimens of $P$. lobata were collected live from $4 \mathrm{~m}$ depth on Saadiyat reef in Abu Dhabi, United Arab Emirates $\left(24^{\circ} 35^{\prime} 56.4^{\prime \prime} \mathrm{N}\right.$, $\left.54^{\circ} 25^{\prime} 17.4^{\prime \prime} \mathrm{E}\right)$ in May 2010 . Fragments $(\sim 10 \times 10 \mathrm{~cm})$ of individual colonies were removed with a hammer and chisel parental colonies were approximately $60 \mathrm{~cm}$ in diameter, typical for colonies of this species in the southern Gulf.

The colonies were taken immediately to New York University Abu Dhabi and maintained for 15 days in individual aquaria at $32{ }^{\circ} \mathrm{C}$ and a salinity of $42 \mathrm{ppt}$ on a 10:14 h light:dark regime under metal halide lights. Afterwards, they were transported submerged in $\sim 500 \mathrm{ml}$ of seawater in individual vessels in an insulated container to the University of Southampton in the UK, where they arrived within $48 \mathrm{~h}$. After arrival, the colonies were introduced to a 5001 unit of the experimental mesocosm of the Coral Reef Laboratory, in which the salinity was adjusted to $42 \mathrm{ppt}$, the value measured in the transport water. Over the first week, light levels were kept low $\left(50 \mu \mathrm{mol}\right.$ photons $\left./ \mathrm{m}^{2} / \mathrm{s}\right)$ to reduce stress. Afterwards, the light intensity was increased to $\sim 150 \mu \mathrm{mol}$ photons/ $\mathrm{m}^{2} / \mathrm{s}$ over a period of 2 weeks. Lamps were operated on a $10 \mathrm{~h} /$ $14 \mathrm{~h}$ light/dark cycle. The temperature in the tanks was kept at $27.5^{\circ} \mathrm{C}$.

P. lobata collected from Fiji reefs in the vicinity of Galao Village were acquired through the ornamental trade (Tropical Marine Centre, London, UK) in November 2009. The corals were received approximately 2 weeks after collection. Small fragments were fixed in EtOH immediately after arrival for symbiont phylotyping. The choice of conspecifics from these two disparate geographical areas as material for comparative physiological experimentation was driven by considering the markedly different annual temperature profiles that characterise these regions (Fig. 1). The Fijian corals were kept in a separate compartment of the mesocosm at a salinity of 33 and a constant temperature of $24.5^{\circ} \mathrm{C}$. A detailed description of the aquarium system is provided in (D'Angelo and Wiedenmann, 2012).

To examine the effects of aquarium culture on the stability of the zooxanthellae symbiosis in $P$. lobata from both locations, fragments were removed from the colonies 15 months after their introduction in our mesocosm for Symbiodinium re-identification.

\subsection{Identification of algal symbionts}

The genetic identification of Symbiodinium at the subclade level was performed by analysis of the ITS2 sequence region of genomic DNA samples. DNA was prepared from coral tissue using a modification of a described method (Sokolov, 2000). Coral tissue was scraped off the skeleton with a scalpel, quickly frozen in liquid nitrogen and crushed to a fine powder which was resuspended in one volume of lysis buffer containing $50 \mathrm{mM}$ Tris- $\mathrm{HCl}(\mathrm{pH} 7.5)$, $100 \mathrm{mM} \mathrm{NaCl}, 10 \mathrm{mM}$ EDTA (pH 8.0) and 1\% SDS and an equal volume of Tris-buffered phenol. After phase separation by centrifugation (14,000 rpm, $4{ }^{\circ} \mathrm{C}, 5 \mathrm{~min}$ ), the aqueous phase was removed and extracted twice with phenol:chloroform:isoamyl-alcohol (25:24:1) and once with chloroform:isoamyl-alcohol (24:1). A last purification step was performed by adding 0.1 volumes of saturated $\mathrm{KCl}$ and incubating on ice for $5 \mathrm{~min}$. After centrifugation, the supernatant was transferred to a new tube and the DNA was precipitated from the supernatant by the addition of one volume of isopropanol, recovered either using a pipette tip or by centrifugation $\left(14,000 \mathrm{rpm}, 4^{\circ} \mathrm{C}, 20 \mathrm{~min}\right)$, washed once with $70 \%$ ethanol, air dried and resuspended in milliQ water.

The DNA region spanning the 18S, ITS1, 5.8S, ITS2, 28S region (Savage et al., 2002) of the Symbiodinium spp. ribosomal DNA was 
amplified with the primers SYM_VAR_FWD (5'CAGCTTCTGGACGTTGYGTTGG3') and SYM_VAR_REV (5'CGGGTTCWCTTGTYTGACTTCATGC $3^{\prime}$ ), designed specifically to anneal in the $18 \mathrm{~S}$ and $28 \mathrm{~S}$ regions of the Symbiodinium spp. (clades A-E) rDNA. The suitability of these primers was confirmed by the successful amplification of the correct fragments from the Symbiodinium subclades A, C and D (data not shown).

Amplification was accomplished in the presence of $200 \mu \mathrm{M}$ of each dNTP, $0.5 \mu \mathrm{M}$ of each primer, 50 ng of gDNA and $0.5 \mu \mathrm{l}$ Advantage 2 polymerase mix (Clontech) per $50 \mu \mathrm{l}$ final reaction volume. The PCR encompassed an initial denaturation step of $1 \mathrm{~min}$ at $98^{\circ} \mathrm{C}$ followed by 35 cycles of denaturation $\left(95^{\circ} \mathrm{C} / 30 \mathrm{~s}\right)$, annealing $\left(62{ }^{\circ} \mathrm{C} / 30 \mathrm{~s}\right)$, and elongation $\left(68^{\circ} \mathrm{C} / 1 \mathrm{~min}\right)$. A final elongation step of 2 min was performed at $68^{\circ} \mathrm{C}$. PCR products were purified using the Jetquick gel extraction spin kit (Genomed), incubated with taq polymerase for $20 \mathrm{~min}$ at $72{ }^{\circ} \mathrm{C}$ to incorporate A-overhangs, and cloned using StrataClone (Stratagene). Plasmid DNA was prepared from E. coli colonies using a QIAprep Spin Miniprep Kit (Qiagen). Sequencing services were provided by Macrogen.

Identification of Symbiodinium types was achieved by comparison of the ITS2 sequence ( $220 \mathrm{bp}$ ) with reference sequences available in Genbank using the BLAST tool (www.ncbi.nlm.nih.gov/ blast).

\subsection{Determination of growth rates}

After 6 months of acclimation to the tank conditions, colonies of Fijian and Arabian P. lobata were fragmented to obtain the experimental replicate colonies and the fragments were attached to glass tiles using cyanoacrylate glue. At four time points over the experimental period of 11 weeks, the wet weight of the replicate colonies was determined. Before each weighing, algal films were removed from the surface of the glass tiles using a toothbrush whilst keeping the colony submerged. Colonies were gently inverted to remove excess water and the base of each glass tile was blotted dry for $10 \mathrm{~s}$ before weighting.

\subsection{Photographic documentation and spectroscopic analyses}

Fluorescent and white light photographs of coral tissue were taken using a Leica DFC420C camera connected to a Leica MZ10F fluorescence microscope as described in (D'Angelo et al., 2012). Excitation and emission spectra were recorded on the live animal tissue of colonies submerged in a small temperature controlled transport aquarium using a fibre optic probe connected to a Varian Cary Eclipse fluorescence spectrophotometer as previously described (D'Angelo et al., 2008; Leutenegger et al., 2007). The excitation spectra of cyan and red light emitting pigments were obtained with emission wavelengths set at $550 \mathrm{~nm}$ and $630 \mathrm{~nm}$, respectively.

\subsection{Heat stress treatment}

Experimental corals were separated in control and treatment groups. Geographical origin was represented by 6 replicate colonies which were derived from two distinct mother colonies. Each group was maintained in a $40 \mathrm{l}$ tank. The tanks received identical light levels (photon flux of $150 \mu \mathrm{mol} / \mathrm{m}^{2} / \mathrm{s}$ ) and the same water movement was created with turbelle pumps (Tunze). Water changes ( $\sim 15 \%)$ were performed daily using water from the main compartment of the mesocosm in which the Abu Dhabi corals were cultured at a salinity of $42 \mathrm{ppt}$. For the Fiji coral tanks, the salinity was adjusted to $33 \mathrm{ppt}$ by dilution with demineralised water.

Prior to the experiment, the corals were acclimated to $27.5^{\circ} \mathrm{C}$ for 1 week. Subsequently, the temperature was gradually increased to $31.5^{\circ} \mathrm{C}$ (ramping $0.5^{\circ} \mathrm{C} /$ day). The temperature was then kept constant at $31.5^{\circ} \mathrm{C}$ for a period of 21 days. Afterwards, the corals were incubated at lower temperatures $\left(\leqslant 27.5^{\circ} \mathrm{C}\right)$ to allow recovery. Two tanks were used as controls for each geographical location: the control tank for Fijian corals was maintained at $24.5^{\circ} \mathrm{C}$; whereas the Arabian corals were kept at $27.5^{\circ} \mathrm{C}$.

The effect of heat stress on the coral holobiont was monitored by recording the number of colonies that appeared completely bleached under the microscope. Additionally, coral fluorescence was documented microscopically and by measuring the fluorescence emission of the host tissue.

\section{Results}

\subsection{Algal symbionts of Abu Dhabi corals}

To help identify a model containing symbionts representative of the Abu Dhabi region, we analysed the symbiont communities in 36 colonies representing six common Gulf coral species.

Sequencing of 146 ITS2 fragments revealed Symbiodininum C3 as the most common symbiont type in these Gulf coral species, namely P. lobata, P. lutea, P. harrisoni, C. microphthalma, F. pallida, P. daedalea and A. clathrata (Table 2). This symbiont was detected either exclusively (in P. lobata and P. lutea) or in combination with other clades, predominantly with A1. In C. microphthalma, both colonies analysed harboured a mixture of $\mathrm{C} 3$ and A1. The same combination was found also in one colony each of $P$. daedalea and $P$. harrisoni, whereas all other colonies of these species were dominated by C3 symbionts. C3 was also prevalent in different colonies of $A$. clathrata. Among the analysed corals species, the greatest diversity in symbiont association was detected in Favia pallida, where types C3, A1 and C15 were found in one single colony. The other samples of this species yielded $\mathrm{A} 1$ or a mixture of $\mathrm{C} 3$ and $\mathrm{A} 1$. The types C15, C21 and C36 were only represented by a single sequence each, indicating the background presence of these symbiont strains in F. pallida, $P$. daedalea, and A. clathrata, respectively. None of the samples contained any detectable clade D symbionts.

\subsection{Culture of P. lobata from the Gulf in a closed aquarium system under controlled conditions}

We established a laboratory culture of $P$. lobata from Abu Dhabi waters in the experimental mesocosm of the Coral Reef Laboratory at the University of Southampton (D'Angelo and Wiedenmann, 2012). All colonies survived removal from the reefs, transport and acclimation to aquarium conditions. After 6 months, the mother colonies were fragmented and glued to colour coded tiles. The growth of the replicate colonies was followed over a period of 11 weeks. By the end of the study period, the replicates had visibly extended over the tiles by encrusting growth (Fig. 2a). The wet weight of the colonies was determined at 3 week intervals. The growth could be best described with an exponential function, resulting in an average increase in wet weight of $50 \%$ by the end of the monitoring period of 11 weeks (Fig. 2b). Normalised to the tissue covered surface area of the replicate colonies at the beginning of the experiment, this increase corresponds to a weight gain of $\sim 1.3 \pm 0.2 \mathrm{~g} / \mathrm{cm}^{2} /$ year.

\subsection{Identification of algal symbionts in laboratory-cultured P. lobata}

Understanding the potential effect of laboratory culture on algal symbiont community composition is of crucial importance for interpreting the responses to experimental treatments. Therefore, we investigated whether the transfer of $P$. lobata from Abu Dhabi and Fiji waters to the aquarium resulted in changes to the dominant symbiont, e.g. due to transport stress, changes in envi- 
Table 2

Symbiodinium clades in corals from the Abu Dhabi coast line.

\begin{tabular}{|c|c|c|c|}
\hline Coral species (collection year) & Analysed colonies & Sequences per individual colony & Clades (sequence ratio) per individual colony \\
\hline Cyphastrea microphthalma (October 2011) & 2 & $\begin{array}{r}11 \\
5\end{array}$ & $\begin{array}{l}\text { C3:A1 }(2: 9) \\
\text { C3:A1 }(3: 2)\end{array}$ \\
\hline Favia pallida (October 2011) & 3 & $\begin{array}{l}5 \\
9 \\
6\end{array}$ & $\begin{array}{l}\text { C3:C15:A1 (1:1:3) } \\
\text { C3:A1 }(1: 8) \\
\text { A1 }(6: 0)\end{array}$ \\
\hline Platygyra daedalea (October 2011) & 2 & $\begin{array}{r}10 \\
8\end{array}$ & $\begin{array}{l}\text { C3:A1 (3:7) } \\
\text { C3:C36 (7:1) }\end{array}$ \\
\hline Porites harrisoni (October 2011) & 3 & $\begin{array}{l}7 \\
8 \\
7\end{array}$ & $\begin{array}{l}\text { C3:A1 (3:4) } \\
\text { C3 }(8: 0) \\
\text { C3 }(7: 0)\end{array}$ \\
\hline Porites harrisoni (September 2012) & 5 & $\begin{array}{l}4 \\
1 \\
3 \\
3 \\
3\end{array}$ & $\begin{array}{l}\text { C3 (4:0) } \\
\text { C3 (n.a.) } \\
\text { C3 (3:0) } \\
\text { C3 }(3: 0) \\
\text { C3 }(3: 0)\end{array}$ \\
\hline Porites lobata (October 2011) & 3 & $\begin{array}{l}5 \\
5 \\
5\end{array}$ & $\begin{array}{l}\text { C3 }(5: 0) \\
\text { C3 }(5: 0) \\
\text { C3 }(5: 0)\end{array}$ \\
\hline Porites lobata (September 2012) & 5 & $\begin{array}{l}5 \\
3 \\
3 \\
3 \\
1\end{array}$ & $\begin{array}{l}\text { C3 }(5: 0) \\
\text { C3 }(3: 0) \\
\text { C3 }(3: 0) \\
\text { C3 (3:0) } \\
\text { C3 (n.a.) }\end{array}$ \\
\hline Porites lutea (September 2012) & 5 & $\begin{array}{l}4 \\
4 \\
4 \\
3 \\
3\end{array}$ & $\begin{array}{l}\text { C3 }(4: 0) \\
\text { C3 }(4: 0) \\
\text { C3 }(4: 0) \\
\text { C3 }(3: 0) \\
\text { C3 }(3: 0)\end{array}$ \\
\hline Acropora clathrata (2010) & 8 & 1 & $\begin{array}{l}\text { C21 (n.a.) } \\
\text { C3 (n.a.) } \\
\text { C3 (n.a.) } \\
\text { C3 (n.a.) } \\
\text { C3 (n.a.) } \\
\text { C3 (n.a.) } \\
\text { C3 (n.a.) } \\
\text { C3 (n.a.) }\end{array}$ \\
\hline Total & 36 & 146 & C3:A1:C15:C21:C36 (104:39:1:1:1) \\
\hline
\end{tabular}

(a)

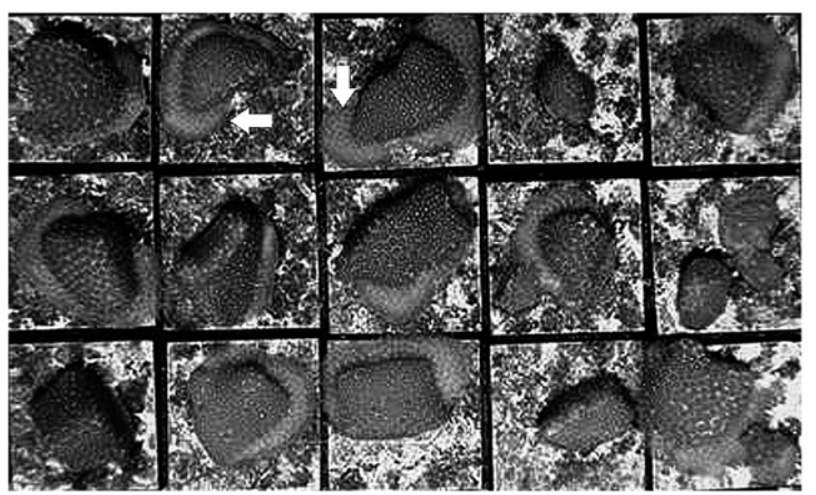

(b)

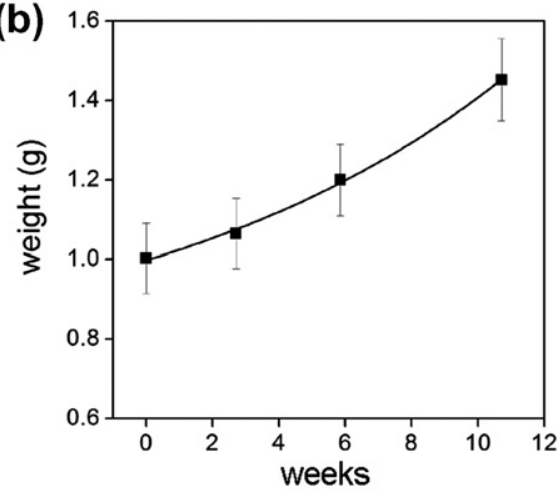

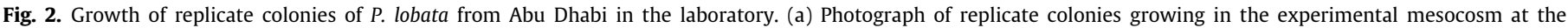

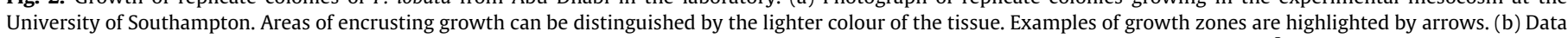

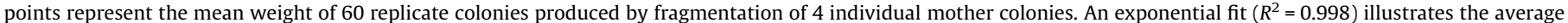
weight gain over a time course of 11 weeks. Error bars denote the standard error of the means.

ronmental conditions, or due to the exchange of symbionts (Baker et al., 2004; Berkelmans and van Oppen, 2006) with other tank inhabitants. We determined the dominant Symbiodinium associated with $P$. lobata after 15 months of laboratory culture and compared the composition with those from samples fixed immediately after collection in the field. The analysis of four genotypes of $P$. lobata derived from 4 individual colonies from Abu Dhabi waters after 15 months of laboratory culture found
C3 as the only symbiont type (Table 3). In contrast, P. lobata samples from Fiji harboured exclusively C15, both after collection and after 15 months of growth in captivity (Table 3).

\subsection{Patterns of host fluorescence in P. lobata}

GFP-like proteins can potentially serve as indicators of physiological changes in coral-zooxanthellae association (D'Angelo 
Table 3

Symbiodinium clades in P. lobata before and after 15 months of laboratory culture.

\begin{tabular}{llll}
\hline Origin & $\begin{array}{l}\text { Analysed } \\
\text { colonies }\end{array}$ & Sequences & Clades \\
\hline Abu Dhabi & 8 & 30 & C3 \\
$\begin{array}{l}\text { NOCS mesocosm (Abu Dhabi } \\
\quad \text { origin) }\end{array}$ & 4 & 16 & C3 \\
Fiji & 4 & 14 & C15 \\
NOCS mesocosm (Fiji origin) & 3 & 9 & C15 \\
\hline
\end{tabular}

et al., 2012, 2008; Dove et al., 2006; Smith-Keune and Dove, 2007). Therefore, we examined the specific complement of host pigments for the model corals, determining the excitation and emission spectra in situ after 15 months of aquarium culture. When excited with blue light, $P$. lobata from Abu Dhabi exhibited cyan fluorescence in the polyps and the coenosarc (Fig. 3a). Similarly, emission in the cyan spectral region was detected in animals originating from Fiji, although in these corals the intensity tended to be stronger in the polyps compared to the coenosarc (Fig. 3b). In agreement with a detailed study of the expression patterns of GFP-like proteins (D'Angelo et al., 2012), the red fluorescence was regularly observed in the growing margins in samples from both origins.

Spectroscopic analyses performed in situ in corals from Abu Dhabi, revealed the presence of a cyan fluorescent protein (CFP) with excitation and emission maxima at $466 \mathrm{~nm}$ and $490 \mathrm{~nm}$ respectively (Fig. 3c). The excitation/emission maxima of the CFP for Fiji samples were located at $486 \mathrm{~nm} / 498 \mathrm{~nm}$ (Fig. 3d). A red fluorescent protein characterised by excitation maximum at $574 \mathrm{~nm}$ and emission maximum at $610 \mathrm{~nm}$ was detected in the margins of representative colonies from both locations (Fig. 3e and f).

\subsection{Heat stress responses of $P$. lobata from different geographical origins}

We tested whether the thermal tolerance of Abu Dhabi corals is retained under laboratory conditions. For this purpose, we examined the response of $P$. lobata from Abu Dhabi and from Fiji to a 21-day heat stress treatment. We used a fibre optic probe coupled to a spectrometer to quantify changes in the cyan fluorescence emission as an indicator of physiological response of the host tissue. Samples from both locations responded to the increased temperatures by a dramatic reduction of cyan fluorescence. After 10 days at $31.5^{\circ} \mathrm{C}$, the cyan fluorescence of both Arabian and Fijian corals was essentially lost (Fig. 4). Fluorescence microscopic inspection revealed that the red fluorescence of the colony margins also vanished within this period (Fig. 4).

Over the course of the treatment, the replicate colonies were inspected under the microscope at weekly intervals to monitor changes to the yellow-brown colouration derived from zooxanthellae pigments visible through the tissue. Colonies were considered to be completely bleached as soon as no yellow-brown colour was visible in the tissue under the microscope (Fig. 4). We note that photographic images of such colonies showed areas which appeared darker (e.g. left margin in the bleached colony in Fig. 4c). This colouration was contributed by pigmentation anomalies of the skeleton, possibly indicating the presence of endolithic algae. The heat-treated colonies of $P$. lobata from Abu Dhabi showed a paler appearance compared to the controls but none of them bleached completely (Fig. 4c). In contrast, $\sim 27 \%$ of all Fijian colonies were completely bleached already after 5 days of treatment. This value increased to $50 \%$ after 2 weeks of heat exposure and, at day 21, all Fijian corals were affected. At this stage, most of the remaining coral tissue was lost. Subsequently, all colonies were

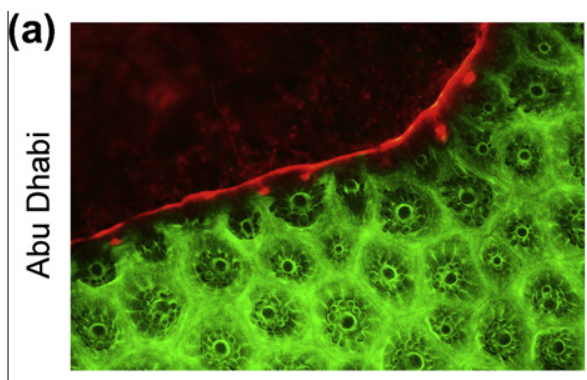

(c)
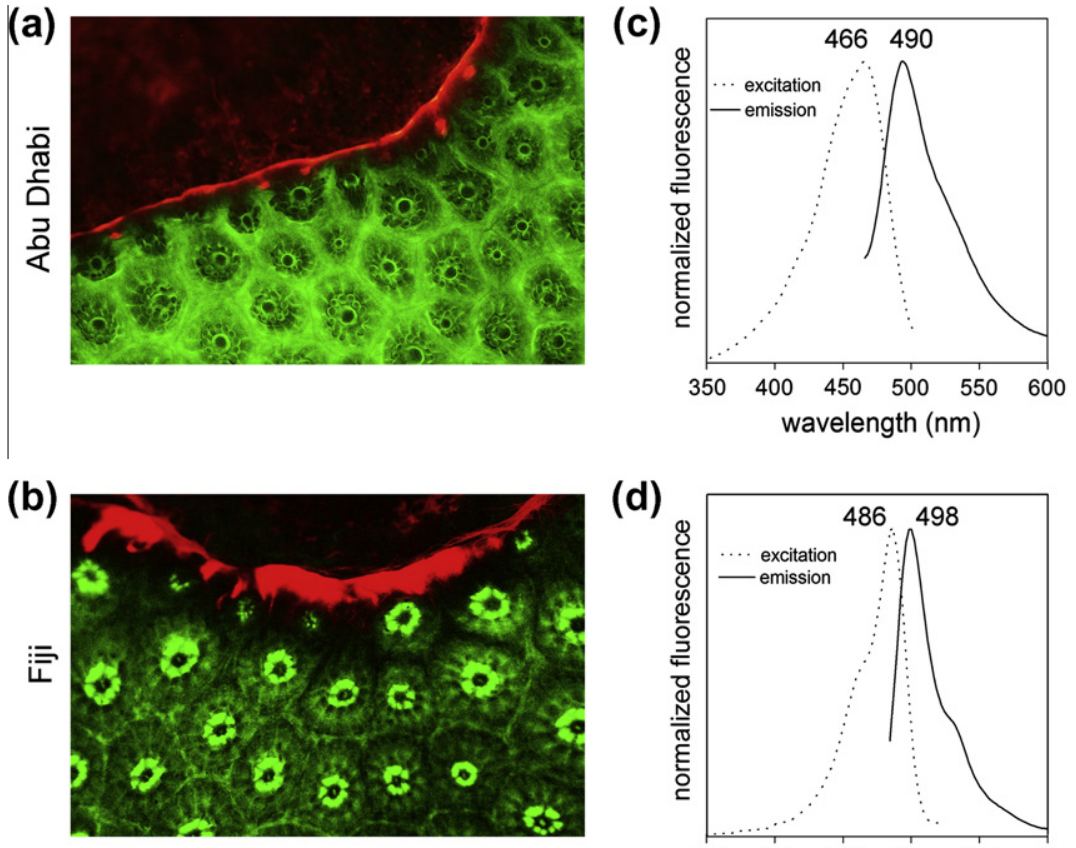

(d)

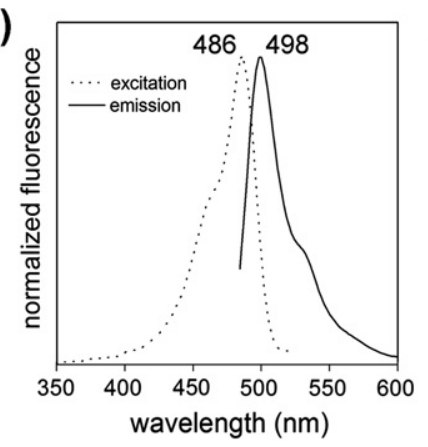

(e)

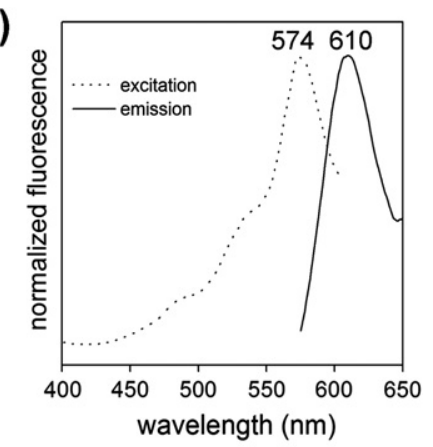

(f)

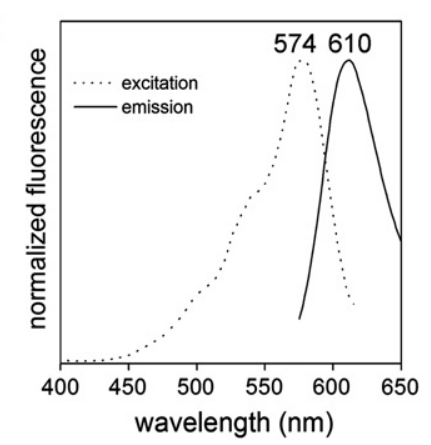

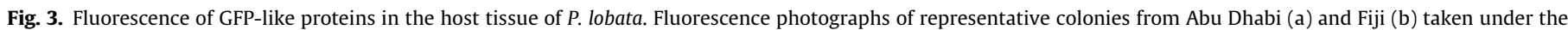

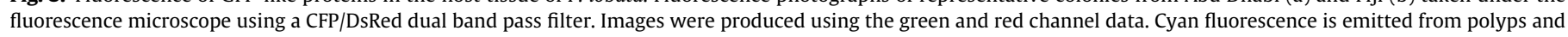

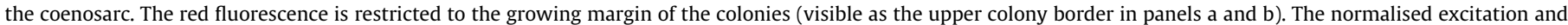

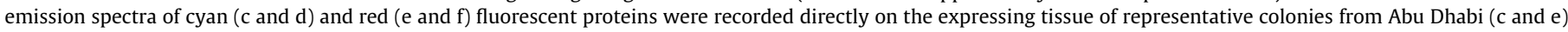
and Fiji ( $\mathrm{d}$ and $\mathrm{f})$. The position of the fluorescence maxima ( $\mathrm{nm}$ ) is given by numbers next to the peaks. 
(a)
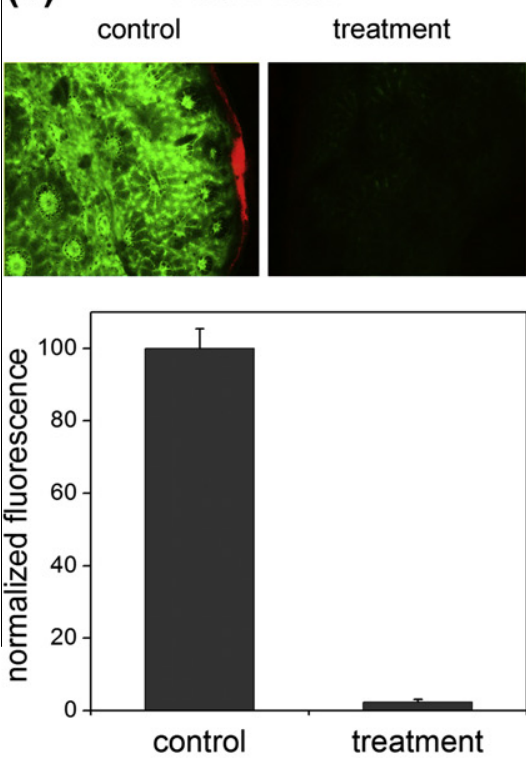

(d)
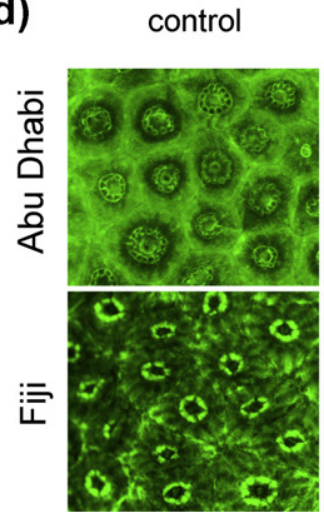

(b) treatment

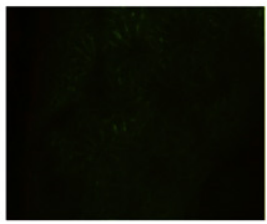

heat stress day 17
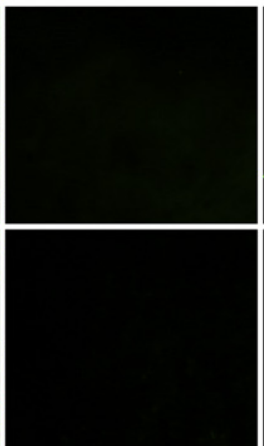

Fiji

control
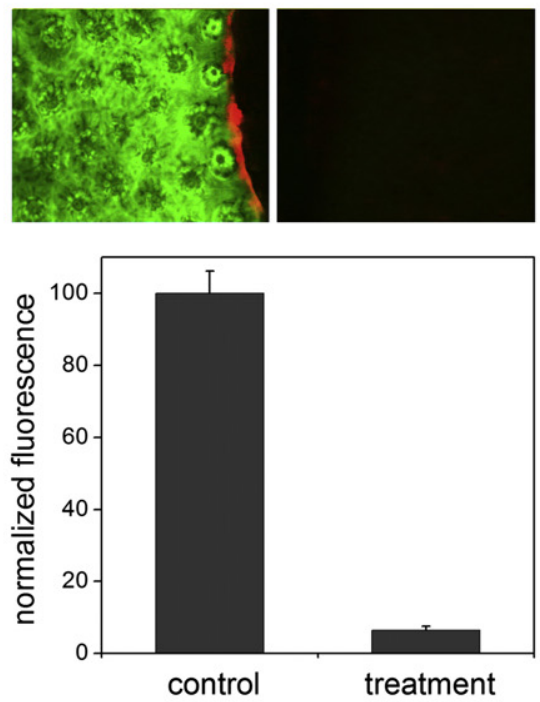

recovery period day 15
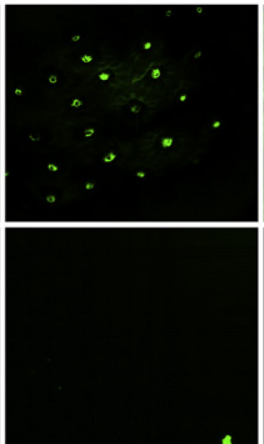

day 56
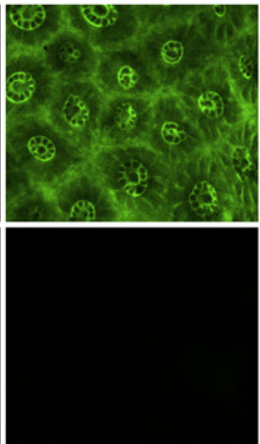

(c) heat-stressed colony
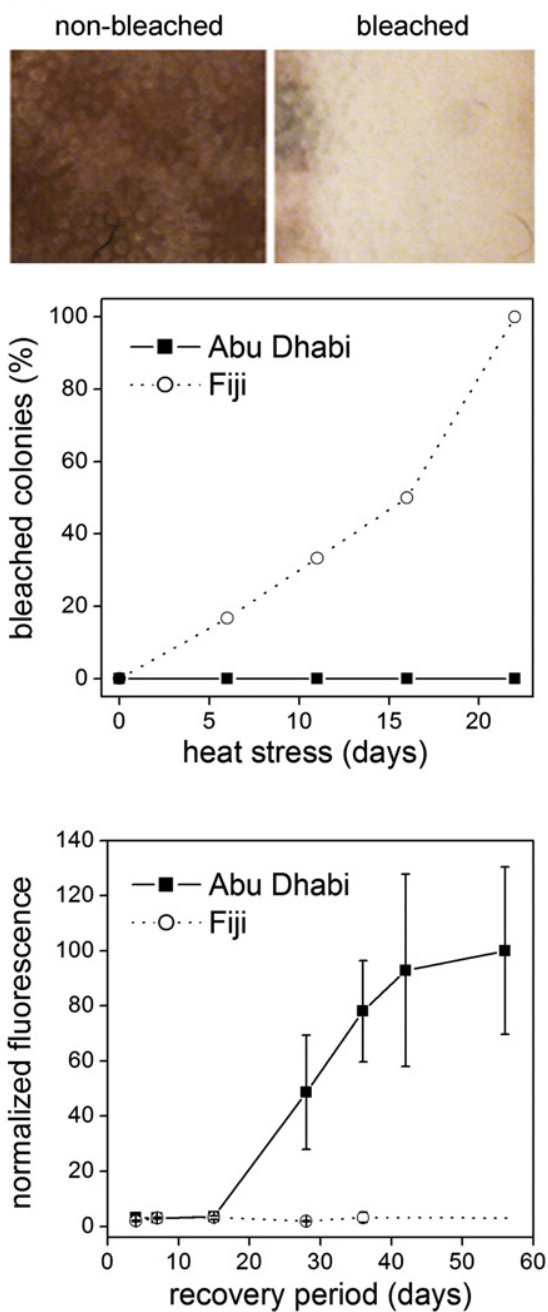

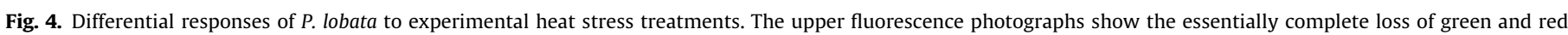

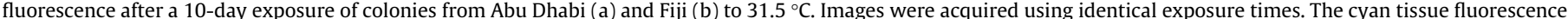

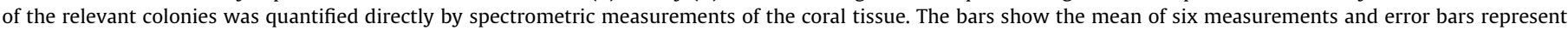

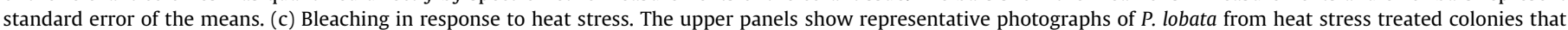

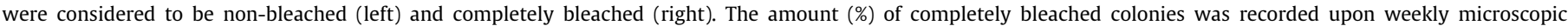

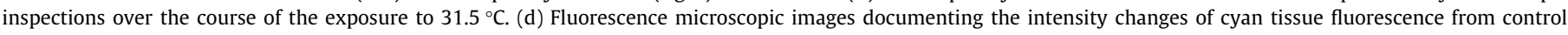

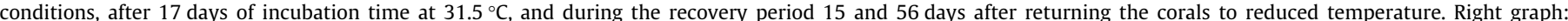

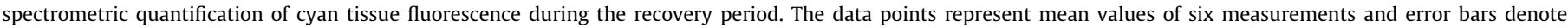
standard error of the means.

transferred to ambient temperatures to monitor the recovery potential over a 2-month period. Fifteen days after being returned to control conditions, host tissue fluorescence was clearly detected under the microscope in the Abu Dhabi samples, particularly in the polyps (Fig. 4d). The cyan fluorescence emission increased over time in all replicates of Abu Dhabi origin, except for one sample which showed no increase in fluorescence and ultimately died. After 56 days of recovery, the surviving colonies displayed tissue fluorescence comparable to the control samples when inspected under the microscope. This observation was confirmed by spectrometric recordings of the tissue fluorescence (Fig. 4d). In contrast, only a few polyps of the Fiji corals exhibited cyan fluorescence under the microscope at the beginning of the recovery period. However, this local emission was below the detection limits of the spectrofluorometic measurements (Fig. 4d). None of these samples recovered their initial fluorescence and eventually all of them died completely.

\section{Discussion}

\subsection{Differences in algal symbiont identity}

In P. lobata and six other common coral species from the coast of Abu Dhabi, Symbiodinium in clade $C$ were the dominant symbionts. This clade accounted for $\sim 73 \%$ of all the ITS2 sequences recovered and was detected in all species studied (Table 2). Most sequences $(\sim 71 \%)$ were $\mathrm{C} 3$, whereas sequences of $\mathrm{C} 15, \mathrm{C} 21$ and C36 were only detected once. Remaining sequences ( $\sim 27 \%)$ were all $\mathrm{A} 1$, which was the second most abundant symbiont type, and which was mostly found in combination with C3 in C. microphthalma, F. pallida, $P$. daedalea and $P$. harrisoni.

Interestingly, Symbiodinium clade D was not represented among the 146 sequences analysed in this study. The preponderance of this clade was first reported from coral species including representatives of the taxa Cyphastrea, Favites and Platygyra from the 
southern Gulf, off the Saudi coast in the aftermath of the 1998 mass bleaching event (Baker et al., 2004). Likewise, in the northern Gulf, off the coast of Kish, Hengam and Larak Islands (Iran), clade D was found in several species including colonies of A. clathrata, $C$. microphthalma, F. pallida and P. daedalea (Mostafavi et al., 2007; Shahhosseiny et al., 2011). It was thus suggested that the dominance of clade D might partially explain the unusual heat tolerance of Gulf corals. The absence of clade D symbionts in corals from Abu Dhabi suggests that the dominance of this clade might represent a regional or temporary phenomenon, promoted by local environmental conditions or recovery from extreme events such as the mass coral bleaching of 1998. Further sampling would help discern the spatial and temporal distribution of symbionts in the Gulf. The prevalence of Symbiodinium C3 in Abu Dhabi corals is surprising, given that this type is considered a "generalist" on Indo-Pacific reefs (LaJeunesse et al., 2003). The fact that Abu Dhabi corals routinely experience summer temperature of up to $36^{\circ} \mathrm{C}$ (Foster et al., 2012) indicates that this Symbiondinium clade can also support symbiotic associations with an exceptional thermotolerance. Therefore, Symbiondinium C3 in Abu Dhabi corals represent an ideal model system for in-depth analyses of the role of algal symbionts in the thermal tolerance of the coral holobiont.

We found Symbiodinium C15 to be the major symbiont associated with corals from the comparably benign temperature regime of Fijian waters. This type has been suggested as contributing to the resistance of Porites spp. to temperature anomalies (LaJeunesse et al., 2003) and it is the characteristic symbiont found in Porites from the Pacific and Indo-Pacific (Lajeunesse, 2005; Barshis et al., 2010). Noteworthily, C15 contributed almost 95\% of the sequences isolated from 31 colonies of $P$. lobata from American Samoa (Barshis et al., 2010).

We showed that the symbiotic association of $P$. lobata from both Abu Dhabi (C3) and from Fiji (C15) is stable under culture conditions in the laboratory. These results are in agreement with previous observations for other corals and sea anemones growing in long-term aquarium culture (Hartle-Mougiou et al., 2012; Smith et al., 2009). The stability of the coral-algal association makes $P$. lobata an excellent model for laboratory experimentation to study the role of C3 and C15 Symbiodinium in the thermal tolerance of this species in different geographical regions.

\subsection{Laboratory cultures of P. lobata}

We successfully established laboratory strains of $P$. lobata from Abu Dhabi, UAE. Encrusting growth contributed significantly to the weight gain of replicate colonies after fragmentation (Fig. 2a). Therefore, the growth characteristics are different from larger, hemispherical colonies, that extend mostly along vertical and horizontal growth axes (Lough and Barnes, 2000). However, a rate of weight gain of $\sim 1.3 \mathrm{~g} \mathrm{~cm}^{-2}$ year $^{-1}$ determined over the first 3 months after fragmentation agrees well with the range of 1.38 $1.63 \mathrm{~g} \mathrm{~cm}^{-2}$ year $^{-1}$ measured previously for $P$. lobata from various locations on the Great Barrier Reef (Lough and Barnes, 2000). These data suggest that growth rates in laboratory culture are similar to those in the field. Moreover, the data from the growth experiment indicate that the number of replicate colonies can be doubled in less than 12 months, providing sufficient material for sustainable experimentation. Aside from $P$. lobata from Abu Dhabi, conspecifics from Fiji could be established as a model for comparative studies of corals originating from habitats with dramatically different temperature regimes.

\subsection{Fluorescent proteins}

A recent study showed that $P$. lobata from different geographical regions express a similar complement of GFP-like proteins.
Typically, cyan FPs can be found in the polyps and the coenosarc and a red FP in the growth zones (D'Angelo et al., 2012). These host pigments belong to the family of GFP-like proteins (Alieva et al., 2008; Dove et al., 2001; Oswald et al., 2007; Wiedenmann et al., 2004,2009 ) of which several (but not all) are regulated at transcriptional level in reef corals in response to changes in environmental conditions; in particular by blue light (Bay et al., 2009; D'Angelo et al., 2008; Desalvo et al., 2008; Leutenegger et al., 2007; Smith-Keune and Dove, 2007). Only recently, the expression of red FPs in the growth zones, wounded or epibiont-infested colony parts of $P$. lobata was correlated with areas characterised by accelerated cell proliferation (D'Angelo et al., 2012). Thus, once the spatial expression pattern of GFP-like proteins and their regulation in a particular species is defined, these pigments constitute powerful biomarkers to monitor physiological responses of corals by non-invasive optical techniques (D'Angelo et al., 2012, 2008; Wiedenmann et al., 2009). Here, we show that the typical expression patterns of FPs are retained after $>15$ months of laboratory culture, suggesting that the aquarium conditions sustain the natural pigmentation of this species.

\subsection{Temperature challenge experiment}

We compared the responses of $P$. lobata from Abu Dhabi and Fiji to increased temperatures to evaluate whether adaptation to temperature regimes at their origin is retained in the laboratory. Microscopic and fluorescence spectrometric measurements of the coral colouration were used to monitor responses of host and symbionts to elevated temperatures.

We found that the FP-derived host tissue fluorescence of $P$. lobata from both geographical regions was dramatically reduced when temperatures were increased. These observations are in agreement with previous observations that also showed a loss of fluorescence under heat stress in other species (Desalvo et al., 2008; SmithKeune and Dove, 2007). Our results demonstrate clearly that FP fluorescence of $P$. lobata can be used for non-invasive optical monitoring of the stress response of the host tissue. Regarding the putative photoprotective function of GFP-like proteins (Dove et al., 2001; Salih et al., 2000; Wiedenmann et al., 1999), the consistent downregulation under heat stress does not support any superior FP-mediated protection of the experimental Abu Dhabi specimens.

Interestingly, microscopic inspections revealed that only $P$. lobata samples from Fiji displayed complete loss of zooxanthellae pigment in the coral tissue in response to the increased temperatures. Although the Abu Dhabi samples showed a visible paling, none of the colonies bleached completely.

Cyan fluorescence emission of the host tissue was fully regained in heat-treated $P$. lobata from Abu Dhabi after approximately 2 months of recovery at reduced temperatures. In contrast, replicates from Fijian colonies did not show comparable signs of recovery after the temperature was reduced and eventually all of the heat treated colonies died. These findings suggest that adaptation to different thermal environments has a long-term influence on the potential of the $P$. lobata to respond to episodes of high temperature and that the samples from Abu Dhabi are more tolerant of the high temperatures in experimental treatments. Since Gulf corals are increasingly endangered in their native habitat (Burt et al 2008, 2011, 2012), it was suggested that these uniquely thermally adapted genotypes should be conserved, or perhaps even transplanted, for the benefit of other reefs that are expected to experience similar temperature extremes by 2099 as those currently experienced by the Gulf (Riegl et al., 2011). Such a strategy would only make sense if the thermal tolerance of Gulf corals was indeed retained ex situ.

The temperature used in our experimental treatments was well below the maximum temperature that Abu Dhabi corals experi- 
ence in their natural habitat. Therefore, it is not yet possible to judge the extent to which the observed heat tolerance of Gulf corals is the result of thermal tolerance on the part of the corals or their algal symbionts, by transient thermal acclimatisation, or by the unique water chemistry of the Gulf, including its exceptionally high salinity.

\section{Conclusion}

We characterised $P$. lobata from two locations with strongly differing temperature regimes. We found that neither association with Symbiodinium in clade D, nor a particular expression pattern of photoprotective host pigments could be solely responsible for the exceptional thermal tolerance of corals from the Gulf. The prevalence of the "generalist" C3 Symbiodinium in Abu Dhabi corals calls for a further evaluation of the role of different symbionts in heat resistance. We demonstrate that our laboratory models can be used in long term experiments under controlled conditions that will greatly facilitate future efforts to decipher the role of the host, symbionts and the abiotic environment in defining thermal tolerance.

Knowledge gained from these experiments should also help evaluate whether Gulf corals could potentially be used for assisted migration in reef restoration projects outside their natural habitat (Riegl et al., 2011).

\section{Acknowledgements}

The study was funded by the Deutsche Forschungsgemeinschaft (DFG Wi1990/2-1 to J.W.), NERC (NE/H012303/1, NE/I01683X/1 to J.W., studentship to B.H./J.W.), the European Research Council under the European Union's Seventh Framework Programme (FP/ 2007-2013) (ERC Grant Agreement n. 311179 to J.W.), and the EPSRC/IFLS ("Bridging the Gap" grant to J.W.). We acknowledge the Tropical Marine Centre, London (UK) and Tropic Marin, Wartenberg (Germany) for sponsoring the Coral Reef Laboratory and the NYU Abu Dhabi Institute for supporting the 2012 "Coral Reefs of the Gulf"-conference and field workshop where this research was discussed. Our appreciation is extended to A. Al-Hemeri of the UAE Federal Environment Agency and A. Al-Cibahy of the Environment Agency of Abu Dhabi for provision of CITES export permits (No. 09FEA555) for UAE corals. Jonathan Coldwell contributed to the analysis of $A$. clathrata zooxanthellae.

\section{References}

Alieva, N.O., Konzen, K.A., Field, S.F., Meleshkevitch, E.A., Hunt, M.E., BeltranRamirez, V., Miller, D.J., Wiedenmann, J., Salih, A., Matz, M.V., 2008. Diversity and evolution of coral fluorescent proteins. PLoS One 3, e2680.

Allemand, D., Ferrier-Pagès, C., Furla, P., Houlbrèque, F., Puverel, S., Reynaud, S. Tambutté, É., Tambutté, S., Zoccola, D., 2004. Biomineralisation in reef-building corals: from molecular mechanisms to environmental control. C.R. Palevol 3 , 453-467.

Baker, A.C., 2001. Reef corals bleach to survive change. Nature 411, 765-766.

Baker, A.C., Glynn, P.W., Riegl, B., 2008. Climate change and coral reef bleaching: an ecological assessment of long-term impacts, recovery trends and future outlook. Estuar. Coast. Shelf Sci. 80, 435-471.

Baker, A.C., Starger, C.J., McClanahan, T.R., Glynn, P.W., 2004. Coral reefs: corals' adaptive response to climate change. Nature 430, 741.

Barshis, D.J., Stillman, J.H., Gates, R.D., Toonen, R.J., Smith, L.W., Birkeland, C., 2010 Protein expression and genetic structure of the coral Porites lobata in an environmentally extreme Samoan back reef: does host genotype limit phenotypic plasticity? Mol. Ecol. 19, 1705-1720.

Bay, L.K., Ulstrup, K.E., Nielsen, H.B., Jarmer, H., Goffard, N., Willis, B.L., Miller, D.J. Van Oppen, M.J., 2009. Microarray analysis reveals transcriptional plasticity in the reef building coral Acropora millepora. Mol. Ecol. 18, 3062-3075.

Berkelmans, R., van Oppen, M.J.H., 2006. The role of zooxanthellae in the thermal tolerance of corals: a 'nugget of hope' for coral reefs in an era of climate change. Proc. R. Soc. B - Biol. Sci. 273, 2305-2312.

Brown, B.E., 1997. Coral bleaching: causes and consequences. Coral Reefs 16 (Suppl.), S129-S138.
Buddemeier, R.W., Fautin, D.G., 1993. Coral bleaching as an adaptive mechanism - a testable hypothesis. Bioscience 43, 320-326.

Burt, J., Al-Khalifa, K., Khalaf, E., AlShuwaik, B., Abdulwahab, A., 2012. The continuing decline of coral reefs in Bahrain. Mar. Pollut. Bull.http://dx.doi.org/ 10.1016/j.marpolbul.2012.08.022.

Burt, J., Bartholomew, A., Usseglio, P., 2008. Recovery of corals a decade after bleaching in Dubai, United Arab Emirates. Mar. Biol. 154, 27-36.

Burt, J., Al-Harthi, S., Al-Cibahy, A., 2011. Long-term impacts of coral bleaching events on the world's warmest reefs. Mar. Environ. Res. 72, 225-229.

Choresh, O., Loya, Y., Muller, W.E., Wiedenmann, J., Azem, A., 2004. The mitochondrial $60-\mathrm{kDa}$ heat shock protein in marine invertebrates: biochemical purification and molecular characterization. Cell Stress Chaperones 9, 38-48.

Coles, S.L., 1997. Reef corals occurring in a highly fluctutating temperature environment at Fahal Island, Gulf of Oman (Indian Ocean). Coral Reefs 16, 269-272.

Coles, S.L., 2003. Coral species diversity and environmental factors in the Arabian Gulf and the Gulf of Oman: a comparison to the Indo-Pacific region. Atoll Res. Bull. 507, 1-19.

Cunning, R., Baker, A.C., 2012. Excess symbionts increase the susceptibility of reef corals to bleaching. Nat. Clim. Change. http://dx.doi.org/10.1038/nclimate1711.

Coles, S.L., Brown, B.E., 2003. Coral bleaching-capacity for acclimatization and adaptation. Adv. Mar. Biol. 46, 183-223.

D’Angelo, C., Smith, E.G., Oswald, F., Burt, J., Tchernov, D., Wiedenmann, J., 2012. Locally accelerated growth is part of the innate immune response and repair mechanisms in reef-building corals as detected by green fluorescent protein (GFP)-like pigments. Coral Reefs 31, 1045-1056.

D’Angelo, C., Wiedenmann, J., 2012. An experimental mesocosm for long-term studies of reef corals. J. Mar. Biol. Assoc. UK 92, 769-775.

D’Angelo, C., Denzel, A., Vogt, A., Matz, M.V., Oswald, F., Salih, A., Nienhaus, G.U. Wiedenmann, J., 2008. Blue light regulation of host pigment in reef-building corals. Mar. Ecol. Prog. Ser. 364, 97-106.

Desalvo, M.K., Voolstra, C.R., Sunagawa, S., Schwarz, J.A., Stillman, J.H., Coffroth, M.A., Szmant, A.M., Median, M., 2008. Differential gene expression during thermal stress and bleaching in the Caribbean coral Montastraea faveolata. Mol. Ecol. 17, 3952-3971.

Douglas, A.E., 2003. Coral bleaching-how and why? Mar. Pollut. Bull. 46, 385-392.

Dove, S., Ortiz, J.C., Enriquez, S., Fine, M., Fisher, P., Iglesias-Prieto, R., Thornhill, D., Hoegh-Guldberg, O., 2006. Response of holosymbiont pigments from the scleractinian coral Montipora monasteriata to short-term heat stress. Limnol. Oceanogr. 51, 1149-1158.

Dove, S.G., Hoegh-Guldberg, O., Ranganathan, S., 2001. Major colour patterns of reef-building corals are due to a family of GFP-like proteins. Coral Reefs 19, 197-204.

Dunlap, W.C., Shick, J.M., 1998. Ultraviolet radiation-absorbing mycosporine-like amino acids in coral reef organisms: a biochemical and environmental perspective. J. Phycol. 34, 418-430.

Forsman, Z., Barshis, D., Hunter, C., Toonen R., 2009. Shape-shifting corals: Molecular markers show morphology is evolutionarily plastic in Porites.

Foster, K., Foster, F., Al Cibahy, A., Al Harthi, S., Riegl, B., 2012. Environmental setting and temporal trends in southeastern Gulf coral communities. In: Riegl, B., Purkis, S. (Eds.), Coral Reefs of the Gulf: Adaptation to Climatic Extremes. Springer, Dordrecht.

Ghavam Mostafavi, P., Fatemi, S., Shahhosseiny, M., Hoegh-Guldberg, O., Loh, W. 2007. Predominance of clade D Symbiodinium in shallow-water reef-building corals off Kish and Larak Islands (Persian Gulf, Iran). Mar. Biol. 153, 25-34.

Glynn, P., 1996. Coral reef bleaching: facts, hypotheses and implications. Glob. Change Biol. 2, 495-509.

Goulet, T.L., 2006. Most corals may not change their symbionts. Mar. Ecol.Prog. Ser. $321,1-7$.

Goulet, T.L., 2007. Most scleractinian corals and octocorals host a single symbiotic zooxanthella clade. Mar. Ecol. Prog. Ser. 335, 243-248.

Hartle-Mougiou, K., D’Angelo, C., Smith, E.G., Burt, J., West, P., Wiedenmann, J., 2012. Diversity of zooxanthellae from corals and sea anemones after long-term aquarium culture. J. Mar. Biol. Assoc. UK 92, 687-691.

Hughes, T.P., Baird, A.H., Bellwood, D.R., Card, M., Connolly, S.R., Folke, C., Grosberg, R., Hoegh-Guldberg, O., Jackson, J.B.C., Kleypas, J., Lough, J.M., Marshall, P., Nystroem, M., Palumbi, S.R., Pandolfi, J.M., Rosen, B., Roughgarden, J., 2003. Climate change, human impacts, and the resilience of coral reefs. Science 301, 929-933.

Jones, A.M., Berkelmans, R., Van Oppen, M.J.H., Mieog, J.C., Sinclair, W., 2008. A community change in the algal endosymbionts of a scleractinian coral following a natural bleaching event: field evidence of acclimatization. Proc. R. Soc. London, Ser. B: Biol. Sci. 275, 1359-1365.

Kinsman, D.J.J., 1964. Reef coral tolerance of high temperatures and salinities. Nature 202, 1280-1282.

Lajeunesse, T.C., 2005. "Species" radiations of symbiotic dinoflagellates in the Atlantic and Indo-Pacific since the Miocene-Pliocene transition. Mol. Biol. Evol. $22,570-581$.

LaJeunesse, T.C., Loh, W., van Woesik, R., Hoegh-Guldberg O., Schmidt, G.W., Fitt, W.K., 2003. Low symbiont diversity in southern Great Barrier Reef corals, relative to those of the Caribbean. Limnol. Oceanogr. 48, 2046-2054.

Leewis, R., Janse, M. (Eds.), 2008. Advances in Coral Husbandry in Public Aquariums. Burgers Zoo, Arnhem, Netherland.

Lesser, M.P., 1996. Elevated temperatures and ultraviolet radiation cause oxidative stress and inhibit photosynthesis in symbiotic dinoflagellates. Limnol. Oceanogr. 41, 271-283. 
ARTICLE IN PRESS

10

B. Hume et al./ Marine Pollution Bulletin $x x x$ (2013) $x x x-x x x$

Lesser, M.P., 2006. Oxidative stress in marine environments: biochemistry and physiological ecology. Annu. Rev. Physiol. 68, 253-278.

Leutenegger, A., D’Angelo, C., Matz, M.V., Denzel, A., Oswald, F., Salih, A., Nienhaus, G.U., Wiedenmann, J., 2007. It's cheap to be colorful. Anthozoans show a slow turnover of GFP-like proteins. FEBS J. 274, 2496-2505.

Lough, J.M., Barnes, D.J., 2000. Environmental controls on growth of the massive coral Porites. J. Exp. Mar. Biol. Ecol. 245, 225-243.

Muscatine, L., 1990. The role of symbiotic algae in carbon and energy flux in reef corals. In: Dubinsky, Z. (Ed.), Ecosystems of the World: Coral Reefs. Elsevier, New York, pp. 75-78.

Oswald, F., Schmitt, F., Leutenegger, A., Ivanchenko, S., D’Angelo, C., Salih, A., Maslakova, S., Bulina, M., Schirmbeck, R., Nienhaus, G.U., Matz, M.V., Wiedenmann, J., 2007. Contributions of host and symbiont pigments to the coloration of reef corals. FEBS J. 274, 1102-1109.

Purkis, S.J., Rowlands, G.P., Riegl, B.M., Renaud, P.G., 2010. The paradox of tropical karst morphology in the coral reefs of the arid Middle East. Geology 38, 227230.

Riegl, B.M., Purkis, S.J., Al-Cibahy, A.S., Abdel-Moati, M.A., Hoegh-Guldberg, O., 2011 Present limits to heat-adaptability in corals and population-level responses to climate extremes. PLoS One 6, e24802.

Rowan, R., Knowlton, N., Baker, A., Jara, J., 1997. Landscape ecology of algal symbionts creates variation in episodes of coral bleaching. Nature 388, 265-269.

Salih, A., Larkum, A., Cox, G., Kuhl, M., Hoegh-Guldberg, O., 2000. Fluorescent pigments in corals are photoprotective. Nature 408, 850-853.

Savage, A.M., Goodson, M.S., Visram, S., Trapido-Rosenthal, H., Wiedenmann, J., Douglas, A.E., 2002. Molecular diversity of symbiotic algae at the latitudinal margins of their distribution: dinoflagellates of the genus Symbiodinium in corals and sea anemones. Mar. Ecol. Prog. Ser. 244, 17-26.

Shahhosseiny, M.H., Ghavam Mostafavi, P., Reza Fatemi, S.M., Karimi, E., 2011. Clade identification of symbiotic zooxanthellae of dominant sclerectinian coral species of intertidal pools in Hengam Island. Afr. J. Biotech. 10, 1502-1506.

Sheppard, C.R., 2003. Predicted recurrences of mass coral mortality in the Indian Ocean. Nature 425, 294-297.

Smith-Keune, C., Dove, S., 2007. Gene expression of a green fluorescent protein homolog as a host-specific biomarker of heat stress within a reef-building coral. Mar. Biotechnol. 10, 1-15.

Smith, D.J., Suggett, D.J., Baker, N.R., 2005. Is photoinhibition of zooxanthellae photosynthesis the primary cause of thermal bleaching in corals? Glob. Change Biol. 11, 1-11.
Smith, R.T., Pinzón, J.H., LaJeunesse, T.C., 2009. Symbiodinium (Dinophyta) diversity and stability in aquarium corals. J. Phycol. 45, 1030-1036.

Sokolov, E.P., 2000. An improved method for DNA isolation from mucopolysaccharide-rich molluscan tissues. J. Mollus. Stud. 66, 573-575.

Suggett, D.J., Warner, M.E., Smith, D.J., Davey, P., Hennige, S., Baker, N.R., 2008. Photosynthesis and production of hydrogen peroxide by Symbiodinium (Pyrrhophyta) phylotypes with different thermal tolerances. J. Phycol. 44, 948-956.

Tchernov, D., Kvitt, H., Haramaty, L., Bibby, T.S., Gorbunov, M.Y., Rosenfeld, H., Falkowski, P.G., 2011. Apoptosis and the selective survival of host animals following thermal bleaching in zooxanthellate corals. Proc. Natl. Acad. Sci. USA 108, 9905-9909.

Veron, J.E.N., 2000. Corals of the World. Australian Institute of Marine Science Townsville.

Wagner, D.E., Kramer, P., van Woesik, R., 2010. Species composition, habitat, and water quality influence coral bleaching in southern Florida. Mar. Ecol. Prog. Ser. 408, 65-78.

Weis, V.M., Davy, S.K., Hoegh-Guldberg, O., Rodriguez-Lanetty, M., Pringle, J.R., 2008. Cell biology in model systems as the key to understanding corals. Trends Ecol. Evol. 23, 369-376.

Wiedenmann, J., D’Angelo, C., Smith, E.G., Hunt, A.N., Legiret, F.-E., Postle, A.D., Achterberg, E.P., 2012. Nutrient enrichment can increase the susceptibility of reef corals to bleaching. Nat. Clim. Change. http://dx.doi.org/10.1038/ nclimate1661.

Wiedenmann, J., Ivanchenko, S., Oswald, F., Nienhaus, G.U., 2004. Identification of GFP-like proteins in nonbioluminescent, azooxanthellate anthozoa opens new perspectives for bioprospecting. Mar. Biotechnol. 6, 270-277.

Wiedenmann, J., Oswald, F., Nienhaus, G.U., 2009. Fluorescent proteins for live cell imaging: opportunities, limitations, and challenges. IUBMB Life 61, 1029-1042.

Wiedenmann, J., Röcker, C., Funke, W., 1999. The morphs of Anemonia aff. sulcata (Cnidaria, Anthozoa) in particular consideration of the ectodermal pigments. Verhandlungen der G.f.Ö 29, 497-503.

Wilkinson, C., 1998. The 1997-1998 mass bleaching event around the world. In: Wilkinson, C. (Ed.), Status of Coral Reefs of the World:1998. AIMS, Townsville, Australia.

Wooldridge, S.A., 2009. Water quality and coral bleaching thresholds: formalising the linkage for the inshore reefs of the Great Barrier Reef, Australia. Mar. Pollut. Bull. 58, 745-751.

Please cite this article in press as: Hume, B., et al. Corals from the Persian/Arabian Gulf as models for thermotolerant reef-builders: Prevalence of clade C3

Symbiodinium, host fluorescence and ex situ temperature tolerance. Mar. Pollut. Bull. (2013), http://dx.doi.org/10.1016/j.marpolbul.2012.11.032 